Research Article

\title{
Optimization of Process Parameters for Vertical-Faced Polypropylene Bottle Injection Molding
}

\author{
Youmin Wang, Zhichao Yan (D), and Xuejun Shan \\ School of Mechanical and Automotive Engineering, Anhui Polytechnic University, Wuhu, China \\ Correspondence should be addressed to Zhichao Yan; 1148078812@qq.com
}

Received 3 March 2018; Revised 22 April 2018; Accepted 30 April 2018; Published 3 June 2018

Academic Editor: Marco Cannas

Copyright (c) 2018 Youmin Wang et al. This is an open access article distributed under the Creative Commons Attribution License, which permits unrestricted use, distribution, and reproduction in any medium, provided the original work is properly cited.

In order to obtain the optimal combination of process parameters for vertical-faced polypropylene bottle injection molding, with UG, the model of the bottle was drawn, and then, one module and sixteen-cavity injection molding system was established and analyzed using Moldflow. For filling and maintaining pressure during the process of infusion bottle injection molding, the orthogonal test table L25 $\left(5^{6}\right)$ using CAE was designed for injection molding of the bottle, with six parameters such as melt temperature, mold temperature, injection pressure, injection time, dwell pressure, and dwell time as orthogonal test factors. By finding the best combination of process parameters, the orthogonal experiment was completed, the results were analyzed by range analysis, and the order of influence of each process parameter on each direction of optimization was obtained. The prediction dates of the infusion bottle were gained under various parameters, a comprehensive quality evaluation index of the bottle was formulated, and the multiobjective optimization problem of injection molding process was transformed into a single-objective optimization problem by the integrated weighted score method. The bottle parameters were optimized by analyzing the range date of the weighted scoring method, and the best parameter combination such as melt temperature $200^{\circ} \mathrm{C}$, mold temperature $80^{\circ} \mathrm{C}$, injection pressure $40 \mathrm{MPa}$, injection time $2.1 \mathrm{~S}$, dwell pressure $40 \mathrm{MPa}$, and dwell time $40 \mathrm{~S}$ was gained.

\section{Introduction}

Polypropylene infusion bottles are currently widely used to hold medical liquids since they have advantages such as better sealing properties, lighter weight, better heat resistance, easy to transport and preserve, and so on. Verticalfaced polypropylene bottles are the preforms used for blow molding, which are mainly produced and processed by injection molding process.

The best combination of process parameter for infusion preform injection of the infusion bottle can be obtained through the orthogonal experiment method, and the injection molding process of the bottle was simulated by using Moldflow to obtain the best combination of process parameters. Jiang-dong and Li-xin [1] completed the selection of injection molding machines, checked for parameters, and so on by Moldflow but did not analyze the impact of each factor to the mold. Ke et al. [2] used Moldflow to establish and analyze the injection mold casting system and obtained the best system but did not point out the factors that affect the casting. Zili et al. [3] applied the orthogonal algorithm to the injection molding process parameter design, selected the parameters for the green performance index, and also proved the feasibility of this method as an example but did not indicate how to optimize the parameters. Wei-ging et al. [4] used Moldflow to determine the best gating position of the mold and set the process parameters but did not indicate the impact of various parameters on the gate. Jin et al. [5] proposed a multiobjective robust design method for injection molding, which is based on the design of internal and external parameters, SNR analysis, and approximate ideal solution but did not draw the specific parameters of the injection molding process. Bo et al. [6] used warpage as quality index, obtained the optimum process parameters by the orthogonal experiment and range analysis methods, but only limited to thinwalled plastic parts. Fengli et al. [7] proposed a model of injection molding process multiobjective robust design and optimization algorithm but did not verify it. The quality of preforms directly affects the quality of blow-molded products; hence, studying the quality of preforms is crucial. The 
optimization of injection molding process parameters of vertical polypropylene preforms was studied, the optimal combination of process parameters was determined after the optimization of each evaluation index, and the injection molding process parameters of synthetic weighted method were simulated and verified.

\section{Infusion Bottle Injection Mold Design}

\subsection{Infusion Bottle Injection Mold Structure Design}

2.1.1. Parting Surface Selection. The parting surface of the mold is the surface formed by the contact of the closed-type core and the cavity. The selection of the parting surface has a direct influence on the determination of the mold structure. It is inseparable from the mold structure and the manufacturing process of the mold, and it directly affects the flow filling process of the molten plastic and the demolding process of the plastic parts. The choice of parting surface is crucial in the design of injection molds. When determining the parting surface of a plastic injection mold, various factors in the molding process need to be taken into consideration. For the parting surface selection, the following factors should be considered: the forming condition, pouring in mold system form, the structure of manufacturability and precision, insert position, shape, exit routes, and mold manufacturing, and the factors such as exhaust and operating process generally need to follow the following basic design principles when choosing a parting surface [9]: (1) the selection of parting surface is based on the contour shape; (2) the projected area of the plastic parts on the parting surface should be minimized; (3) the parting surface structure should be as simple as possible so as to design and manufacture the mold; (4) the selection of parting surface shall ensure the shape, size accuracy, and appearance requirements of the plastic parts; and (5) the parting surface shall be conducive to the stripping, side pumping, and exhaust of plastic parts. In the actual design process, the above principles should be satisfied as far as possible, and the parting surface should be reasonably selected.

After considering the gating system state, the structure of plastic parts technology and accuracy, insert position, shape and withdrawal style, mold manufacturing, gas exhaust, operating process of the plastic parts in the mold, the graph of the bottle parting surface could be gained, as shown in Figure 1 [10].

After determining the parting surface, the number and arrangement of cavities need to be taken into account. Figure 2 is the infusion bottle distributed in two-row and eight-column layout [11]. In order to ensure the quality of plastic products and the complexity of the molding process, after comprehensive analysis, the gating location was chosen as the bottom, and the best gating system was determined. Figure 3 shows the infusion bottle gating system [12].

\subsection{Design of Molding Parts for Injection Mold of Infusion} Bottle. The molding parts of injection molds refer to the parts that form the mold cavity, usually including the core, the cavity, and various forming rods and forming inserts. The forming parts can be divided into the installation part and

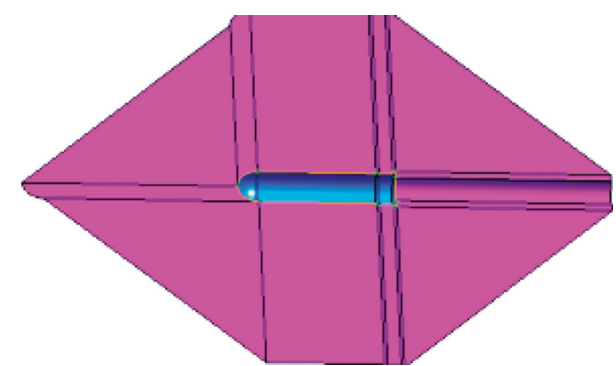

FIgURE 1: Parting surface of the infusion bottle.

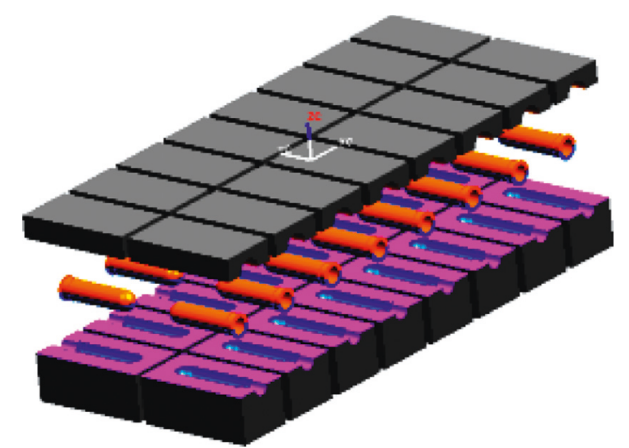

Figure 2: Infusion bottle embryo in two-row and eight-column layout.

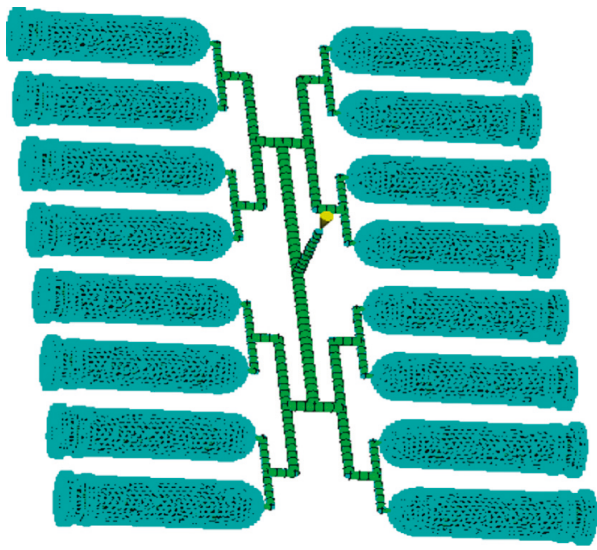

FIGURE 3: Infusion bottle gating system.

the working part. The installation part mainly supports and fixed the forming part, its surface roughness is generally Ra 1.6. The working part is in direct contact with the plastic parts, which is used to form the plastic parts [13]. The surface roughness is determined according to the requirements of the plastic parts, generally not higher than $\mathrm{Ra} 0.4 \mathrm{~mm}$. When making the structure design of molding parts, on the one hand, one should check whether the qualified parts were obtained and, on the other hand, whether processing and manufacturing were facilitated and also note that as far as possible to save valuable mold material, in order to reduce the mold cost [14].

Based on the personal experience of the engineer in mapping the structure of the shape and then in designing the injection mold of molding parts, traditional injection mold design is time-consuming and not economic. In the modern injection molding design, the structure of the plastic parts is 


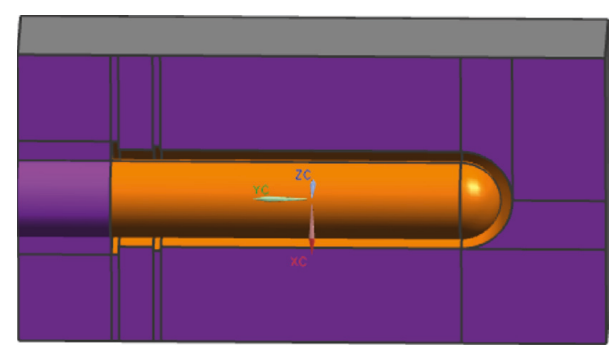

Figure 4: Infusion bottle embryo core cavity structure.

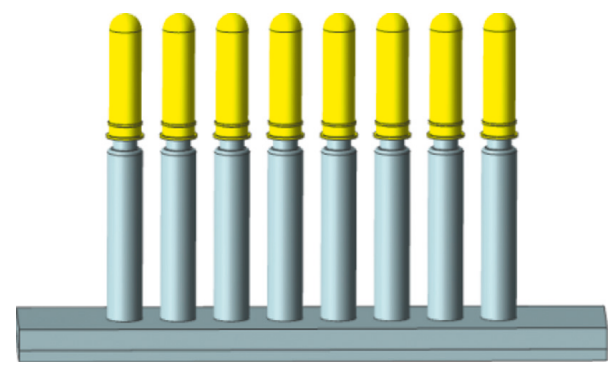

Figure 5: Infusion bottle injection mold side core-pulling mechanism.

usually designed and drawn by using 3D software. Then, make a design drawing of its molded parts. The molding parts of injection molds designed by the modern methods are more accurate, time-saving, and cost-effective [15]. There are two methods for the design of forming parts by using 3D software. One is to automatically model and adopt the modules in the 3D software, such as the Wizard in UG. The second is manual modeling, according to the structure of the plastic parts.

In this topic, the structure of infusion bottleneck parts is relatively simple, and the core, cavity, ejection mechanism, and core-pulling mechanism of the infusion bottle injection mold are mainly designed, and the molded parts are designed using UG software illustration. First of all, using UG to infusion bottle embryo structure modeling 3D model, its shrinkage rate is set at $3 \%$; Through manual modeling method, mold design is performed, various modeling commands in UG are invoked, and the plastic parts are divided and molded by the summation and difference. In the end, the core and cavity are obtained, because the upper and lower parts of the infusion bottle are symmetrical, and the core cavity is the same [16]. The structure of the core cavity of the infusion bottle embryo core obtained by using UG is shown in Figure 4.

\subsection{Infusion Bottle Injection Mold Side Core-Pulling Mech-} anism and Auxiliary Hydraulic System. Side core-pulling mechanism was designed to ensure smooth demolding, and this is shown in Figure 5. This paper used hydraulic loose-core system, as shown in Figure 6 [17].

\subsection{The Design of Infusion Bottle Mold Assembly Drawing.} It not only needs core, cavity, and core-pulling mechanism for a complete injection molding pattern, but also needs mold frame, gating system, cooling system, ejection mechanism, exhaust system to support it, and the final twodimensional engineering drawing is shown in Figure 7 [18].

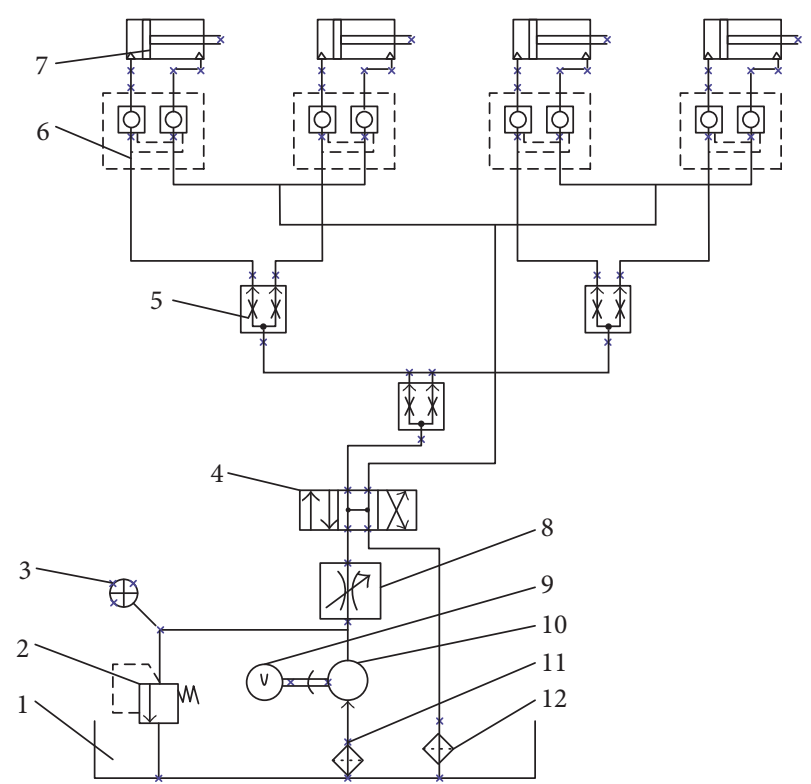

Figure 6: The hydraulic core-pulling system of infusion bottle injection molding: 1 , tank; 2 , relief valve; 3 , pressure gauge; 4 , reversing valve; 5 , dividing-combining valve; 6 , hydraulic lock; 7 , hydraulic cylinder; 8, speed control valve; 9, explosion-proof motor; 10, gear pump; 11, oil filter; and 12, refined oil filter.

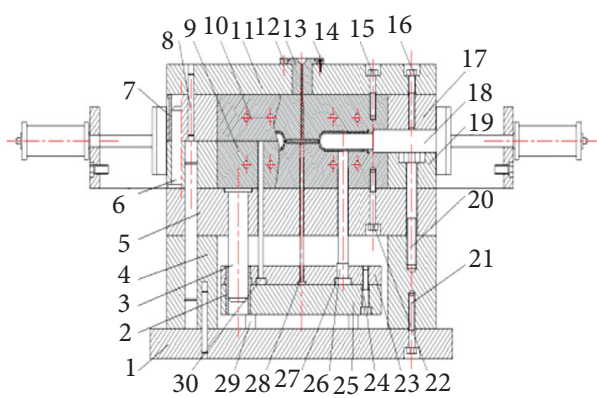

(a)

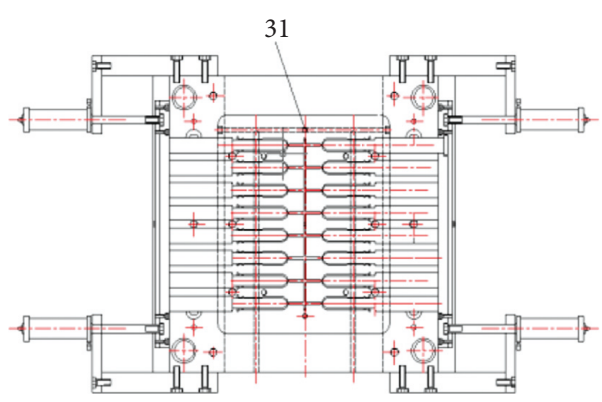

(b)

FIGURE 7: Infusion bottle embryo assembly diagram: 1, bottom clamp plate; 2 , ejector guide pillar; 3 , ejector guide pin; 4 , spacer parallel; 5 , bearing plate; 6 , guide pillar; 7 , guide bush; 8 , dowel; 9 , cores ejector side; 10 , fixed die insert; 11 , fixed clamping plate; 12 , locating ring; 13 , gate; 17 , fixed plate fixed die; 18 , side coredrawing; 19, dynamic model of fixed plate; 23, push plate fixed plate; 25 , stripper; 26, pushrod; 27, pushrod positioning pin; 28, sprue puller; 29, banking pin; 30, release link; 31, panel board dowel; 14, 15, 16, 20, 21, 22, 24, screws. 
TABLE 1: Orthogonal test of six factors and five levels.

\begin{tabular}{|c|c|c|c|c|c|c|}
\hline \multirow[b]{2}{*}{ Levels } & \multicolumn{6}{|c|}{ Factors } \\
\hline & $\begin{array}{l}\text { Melt temperature, } \\
\qquad A\left({ }^{\circ} \mathrm{C}\right)\end{array}$ & $\begin{array}{l}\text { Mold temperature, } \\
\qquad B\left({ }^{\circ} \mathrm{C}\right)\end{array}$ & $\begin{array}{c}\text { Injection pressure, } \\
C(\mathrm{MPa})\end{array}$ & $\begin{array}{c}\text { Injection time, } \\
D(\mathrm{~s})\end{array}$ & $\begin{array}{c}\text { Dwell pressure, } \\
E(\mathrm{MPa}) \\
\end{array}$ & $\begin{array}{c}\text { Dwell time, } \\
\quad F(\mathrm{~s})\end{array}$ \\
\hline 1 & 200 & 20 & 30 & 1.3 & 28 & 20 \\
\hline 2 & 220 & 35 & 35 & 1.5 & 32 & 25 \\
\hline 3 & 240 & 50 & 40 & 1.7 & 36 & 30 \\
\hline 4 & 260 & 65 & 45 & 1.9 & 40 & 35 \\
\hline 5 & 280 & 80 & 50 & 2.1 & 44 & 40 \\
\hline
\end{tabular}

TABLE 2: The results of the orthogonal test and the comprehensive weighted score of embryo injection molding of the infusion bottle.

\begin{tabular}{|c|c|c|c|c|c|c|c|c|c|}
\hline \multirow[t]{2}{*}{ Number } & \multicolumn{2}{|c|}{$\begin{array}{l}\text { Shrinkage } \\
\text { index (\%) }\end{array}$} & \multicolumn{2}{|c|}{$\begin{array}{l}\text { Volumetric } \\
\text { shrinkage (\%) }\end{array}$} & \multicolumn{2}{|c|}{$\begin{array}{l}\text { Residual stress in cavity in } \\
\text { the first direction }(\mathrm{MPa})\end{array}$} & \multicolumn{2}{|c|}{$\begin{array}{l}\text { Residual stress in cavity in } \\
\text { the second direction }(\mathrm{MPa})\end{array}$} & \multirow{2}{*}{$\begin{array}{c}\text { Comprehensive } \\
\text { weighted } \\
\text { score } Y^{*}\end{array}$} \\
\hline & Value & Score & Value & Score & Value & Score & Value & Score & \\
\hline 1 & -1.435 & 48.46 & 14.25 & 55.16 & 46.81 & 86.65 & 61.07 & 78.28 & 65.94 \\
\hline 2 & -1.841 & 62.17 & 14.44 & 56.16 & 48.18 & 89.19 & 58.53 & 75.03 & 71.76 \\
\hline 3 & -1.960 & 66.19 & 14.13 & 54.53 & 49.30 & 91.26 & 62.52 & 80.14 & 73.43 \\
\hline 4 & -1.039 & 35.09 & 14.36 & 55.74 & 51.84 & 95.96 & 68.62 & 87.96 & 62.72 \\
\hline 5 & 0 & 0.00 & 10.22 & 0 & 54.02 & 100.00 & 74.18 & 95.09 & 41.07 \\
\hline 6 & -2.102 & 70.99 & 15.42 & 71.33 & 48.42 & 89.63 & 53.61 & 48.72 & 76.76 \\
\hline 7 & -2.145 & 72.44 & 15.86 & 73.65 & 52.92 & 97.96 & 78.01 & 100.00 & 82.23 \\
\hline 8 & -1.712 & 57.82 & 15.04 & 79.32 & 44.78 & 82.90 & 60.99 & 78.18 & 70.97 \\
\hline 9 & -2.094 & 70.72 & 15.26 & 80.49 & 46.62 & 86.30 & 67.40 & 86.40 & 77.75 \\
\hline 10 & -1.893 & 63.93 & 15.50 & 81.75 & 48.89 & 90.50 & 69.72 & 89.37 & 76.26 \\
\hline 11 & -1.892 & 63.90 & 12.66 & 36.77 & 43.99 & 71.43 & 53.56 & 48.66 & 67.28 \\
\hline 12 & -2.233 & 75.41 & 16.17 & 85.28 & 45.87 & 84.91 & 59.56 & 76.35 & 80.41 \\
\hline 13 & -2.281 & 77.03 & 16.07 & 84.76 & 50.07 & 92.69 & 73.90 & 94.73 & 83.46 \\
\hline 14 & -2.085 & 70.42 & 16.48 & 86.92 & 53.76 & 99.52 & 76.92 & 98.60 & 82.75 \\
\hline 15 & -2.226 & 75.18 & 16.68 & 87.97 & 45.64 & 84.49 & 70.93 & 90.92 & 82.80 \\
\hline 16 & -2.380 & 80.38 & 17.46 & 92.09 & 53.80 & 99.59 & 55.95 & 51.72 & 86.12 \\
\hline 17 & -2.604 & 87.94 & 17.34 & 91.46 & 41.50 & 46.82 & 55.38 & 50.99 & 86.54 \\
\hline 18 & -2.286 & 77.20 & 17.95 & 94.67 & 42.65 & 68.95 & 60.18 & 77.14 & 84.36 \\
\hline 19 & -1.697 & 57.31 & 18.01 & 94.99 & 43.60 & 70.71 & 67.56 & 86.60 & 77.65 \\
\hline 20 & -0.9201 & 31.07 & 17.16 & 90.51 & 48.83 & 90.39 & 71.95 & 92.23 & 66.89 \\
\hline 21 & -2.961 & 100.00 & 18.96 & 100.00 & 41.74 & 47.27 & 51.38 & 0 & 94.31 \\
\hline 22 & -2.425 & 81.90 & 18.88 & 99.58 & 43.29 & 70.14 & 55.83 & 51.57 & 87.76 \\
\hline 23 & -2.412 & 81.46 & 17.95 & 94.67 & 45.32 & 83.89 & 62.43 & 80.03 & 86.85 \\
\hline 24 & -2.457 & 82.98 & 18.38 & 96.94 & 40.96 & 0 & 61.48 & 78.81 & 87.43 \\
\hline 25 & -2.471 & 83.45 & 18.86 & 99.47 & 41.14 & 46.16 & 64.35 & 82.49 & 89.03 \\
\hline
\end{tabular}

\section{Orthogonal Experiment}

In science experiment investigation, sometimes there are only one or two factors. Because there are few factors, the design of experiment, implementation, and analysis are relatively simple. However, in practical situation, there will be more influencing factors so that the scale of the experiment can be quite extensive [19].

Orthogonal test is a method for seeking the best level combination with multiple factors and the minimum test times [16]. After considering the requirements of quality of the infusion bottle comprehensively, six process parameters were selected as the factors of orthogonal test: melt temperature, mold temperature, injection pressure, injection time, dwell pressure, and dwell time, which was marked as $A$, $B, C, D, E$, and $F$, respectively, with five levels (Table 1 ).

After selecting the factors and the level of orthogonal test, the final orthogonal test table was selected according to the orthogonal experiment factors and the interaction between the factors. This paper selects the orthogonal test table of six factors and five levels. Table 2 shows the factor levels of the experiment.

3.1. The Analysis of Injection Molding Parameter Effect Tendency towards Infusion Bottle Sink Index. According to the injection molding results shown in Table 2, the influence level order of each process parameter towards the sink index was obtained as follows: melt temperature $>$ mold temperature $>$ injection time $>$ dwell pressure $>$ dwell time $>$ injection pressure. Table 3 shows the range analysis of the sink index for each parameter.

$K_{1}, K_{2}, K_{3}, K_{4}$, and $K_{5}$ denote, respectively, the sum of the sink index of each factor at five levels, $k_{1}, k_{2}, k_{3}, k_{4}$, and $k_{5}$ denote, respectively, the average of the sum of the sink index of each factor at five levels, and the range is $R$. The trend of 
TABLE 3: The range analysis of the sink index for each process parameter.

\begin{tabular}{lcccccc}
\hline & $A$ & $B$ & $C$ & $D$ & $E$ & $F$ \\
\hline$k_{1}=K_{1} / 5$ & -1.255 & -2.154 & -2.025 & -1.819 & -2.087 & -2.006 \\
$k_{2}=K_{2} / 5$ & -1.989 & -2.250 & -2.056 & -2.170 & -2.117 & -2.150 \\
$k_{3}=K_{3} / 5$ & -2.143 & -2.130 & -1.875 & -2.244 & -2.149 & -2.001 \\
$k_{4}=K_{4} / 5$ & -1.977 & -1.874 & -1.967 & -2.131 & -1.753 & -1.968 \\
$k_{5}=K_{5} / 5$ & -2.545 & -1.502 & -1.988 & -1.545 & -1.804 & -1.816 \\
$R$ & 1.290 & 0.748 & 0.181 & 0.699 & 0.396 & 0.334 \\
Order & 1 & 2 & 6 & 3 & 4 & 5 \\
\hline
\end{tabular}

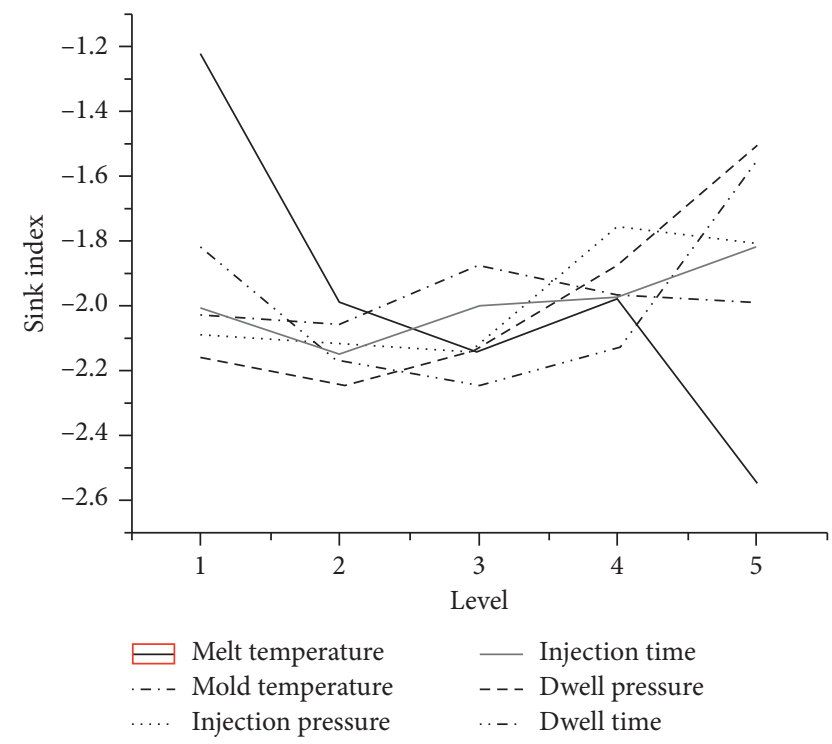

FIGURE 8: The influence of various factors of the orthogonal test on the sink index of infusion bottle embryo parts.

each factor on the shrinkage index was drawn, as shown in Figure 8. The optimal combination was obtained as follows: $A 1 B 5 C 3 D 5 E 4 F 5$, when the melt temperature reached $200^{\circ} \mathrm{C}$, mold temperature reached $80^{\circ} \mathrm{C}$, the injection pressure was $40 \mathrm{MPa}$, the injection time was $2.1 \mathrm{~S}$, the dwell pressure was $40 \mathrm{MPa}$, and the dwell time was $40 \mathrm{~S}$. This combination of process parameters that approved in Moldflow is not included in the existing tests. The shrinkage index is $-0.0709 \%$, which shows the results have been optimized.

3.2. The Analysis of Injection Molding Parameter Effect Tendency towards Infusion Bottle Volumetric Shrinkage. The range analysis of volumetric shrinkage for process parameter is shown in Table 4, and the influence level order of each process parameter towards volumetric shrinkage was obtained as follows: melt temperature $>$ injection time $>$ dwell time$>$ injection pressure $>$ dwell pressure $>$ mold temperature.

The trend of each factor on volumetric shrinkage was drawn as shown in Figure 9. The optimal combination was obtained as follows: $A 1 B 5 C 5 D 5 E 5 F 4$, when the melt temperature reached $200^{\circ} \mathrm{C}$, the mold temperature reached $80^{\circ} \mathrm{C}$, the injection pressure was $50 \mathrm{MPa}$, the injection time was $2.1 \mathrm{~S}$, the dwell pressure was $44 \mathrm{MPa}$, and the dwell time was
TABLE 4: The range analysis of volumetric shrinkage for process parameter.

\begin{tabular}{lcccccc}
\hline & $A$ & $B$ & $C$ & $D$ & $E$ & $F$ \\
\hline$k_{1}=K_{1} / 5$ & 13.480 & 15.750 & 16.612 & 16.158 & 16.338 & 16.610 \\
$k_{2}=K_{2} / 5$ & 15.416 & 16.538 & 16.500 & 16.370 & 15.834 & 16.230 \\
$k_{3}=K_{3} / 5$ & 15.612 & 16.228 & 15.638 & 16.446 & 16.554 & 16.595 \\
$k_{4}=K_{4} / 5$ & 17.584 & 16.498 & 16.378 & 16.762 & 16.378 & 15.562 \\
$k_{5}=K_{5} / 5$ & 18.606 & 15.684 & 15.570 & 14.962 & 15.594 & 15.628 \\
$R$ & 5.126 & 0.854 & 1.042 & 1.800 & 0.960 & 1.048 \\
Order & 1 & 6 & 4 & 2 & 5 & 3 \\
\hline
\end{tabular}

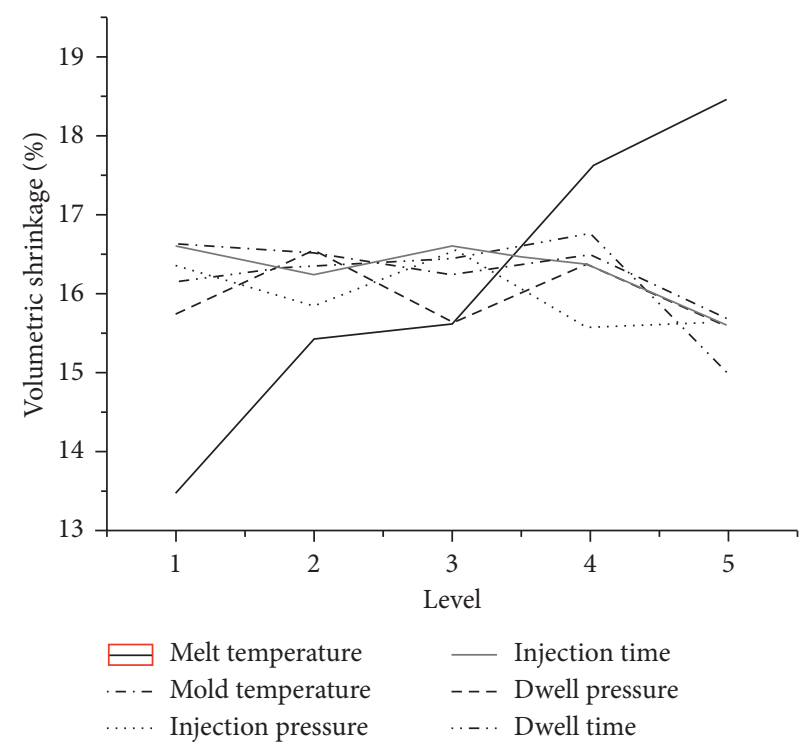

FIgURE 9: The influence of each factor of the orthogonal test on volumetric shrinkage of infusion bottle.

TABLE 5: The range analysis of the residual stress in cavity in the first direction by various process parameters.

\begin{tabular}{lcccccc}
\hline & $A$ & $B$ & $C$ & $D$ & $E$ & $F$ \\
\hline$k_{1}=K_{1} / 5$ & 50.030 & 46.952 & 47.080 & 46.690 & 43.938 & 46.908 \\
$k_{2}=K_{2} / 5$ & 48.326 & 46.352 & 46.232 & 48.380 & 44.516 & 47.115 \\
$k_{3}=K_{3} / 5$ & 47.866 & 46.424 & 47.200 & 46.824 & 45.880 & 47.913 \\
$k_{4}=K_{4} / 5$ & 46.076 & 47.356 & 47.486 & 46.958 & 48.490 & 46.308 \\
$k_{5}=K_{5} / 5$ & 42.490 & 47.704 & 46.790 & 45.936 & 51.964 & 46.384 \\
$R$ & 7.540 & 1.352 & 1.254 & 2.444 & 8.026 & 1.605 \\
Order & 2 & 5 & 6 & 3 & 1 & 4 \\
\hline
\end{tabular}

$35 \mathrm{~S}$. Moldflow is used to verify whether the volumetric shrinkage is $10.27 \%$, which is close to the minimum value in the experimental group.

3.3. The Analysis of the Injection Molding Parameter Effect Tendency towards Infusion Bottle Residual Stress in Cavity in the First Direction. The range analysis of the residual stress in cavity in the first direction by various process parameters is shown in Table 5, and the influence level order of each process parameter towards the residual stress in cavity in the first direction was obtained as follows: dwell pressure $>$ melt temperature $>$ injection time $>$ dwell time $>$ mold temperature $>$ injection pressure. 


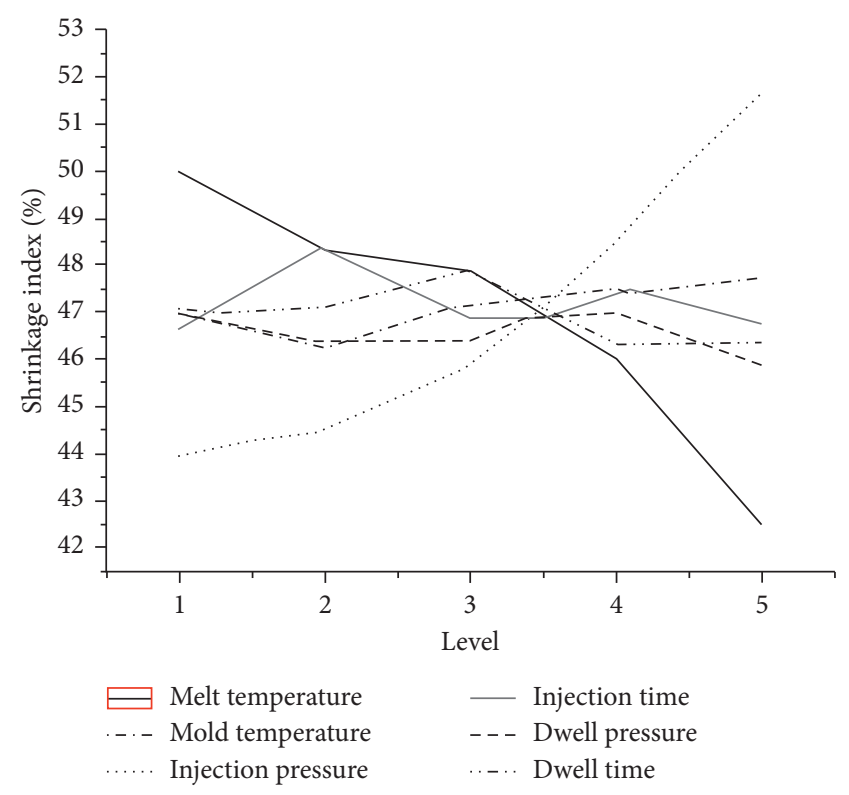

FIGURE 10: The influence of various factors on the residual stress in cavity in the first direction of infusion bottle embryo parts by the orthogonal test.

The effect tendency graph of each factor towards residual stress in cavity in the first direction is shown in Figure 10. The optimal combination was obtained as follows: $A 5 B 2 C 2 D 5 E 1 F 4$, when the melt temperature reached $280^{\circ} \mathrm{C}$, the mold temperature reached $35^{\circ} \mathrm{C}$, the injection pressure was $28 \mathrm{MPa}$, the injection time was $2.1 \mathrm{~S}$, the dwell pressure was $44 \mathrm{MPa}$, and the dwell time was $35 \mathrm{~S}$. Moldflow is used to verify whether the result is $39.98 \mathrm{MPa}$, and the stress is smaller than any of the group of the orthogonal test.

3.4. The Analysis of Injection Molding Parameter Effect Tendency towards Infusion Bottle Residual Stress in Cavity in the Second Direction. The range analysis of the residual stress in cavity in the second direction by various process parameters is shown in Table 6, and the influence level order of each process parameter towards the residual stress in cavity in the second direction was obtained as follows: mold temperature $>$ dwell pressure $>$ melt temperature $>$ dwell time$>$ injection pressure $>$ injection time.

The effect tendency graph of each factor towards residual stress in cavity in the second direction is shown in Figure 11. The optimal combination was obtained as follows: $A 5 B 1 C 4 D 5 E 2 F 5$, when the melt temperature reached $280^{\circ} \mathrm{C}$, the mold temperature reached $20^{\circ} \mathrm{C}$, the injection pressure was $45 \mathrm{MPa}$, the injection time was $2.1 \mathrm{~S}$, the dwell pressure was $32 \mathrm{MPa}$, and dwell time $40 \mathrm{~S}$. Moldflow is used to verify whether the result is $50.50 \mathrm{MPa}$, and the stress is smaller than any of the group by the orthogonal test.

\section{Optimization of Injection Molding Parameters of Infusion Bottle}

4.1. Design Variable. The sink index, volumetric shrinkage, residual stress in cavity in the first direction, residual stress
TABLE 6: The range analysis of the residual stress in cavity in the second direction by various process parameters.

\begin{tabular}{lcccccc}
\hline & $A$ & $B$ & $C$ & $D$ & $E$ & $F$ \\
\hline$k_{1}=K_{1} / 5$ & 64.984 & 55.114 & 64.744 & 64.482 & 61.970 & 68.978 \\
$k_{2}=K_{2} / 5$ & 65.946 & 61.462 & 62.612 & 63.916 & 60.804 & 61.955 \\
$k_{3}=K_{3} / 5$ & 66.974 & 64.004 & 65.504 & 62.556 & 62.148 & 64.097 \\
$k_{4}=K_{4} / 5$ & 62.204 & 68.396 & 61.894 & 65.824 & 64.782 & 61.942 \\
$k_{5}=K_{5} / 5$ & 59.094 & 70.226 & 64.448 & 62.424 & 69.498 & 61.802 \\
$R$ & 7.880 & 15.112 & 3.610 & 3.400 & 8.694 & 7.176 \\
Order & 3 & 1 & 5 & 6 & 2 & 4 \\
\hline
\end{tabular}

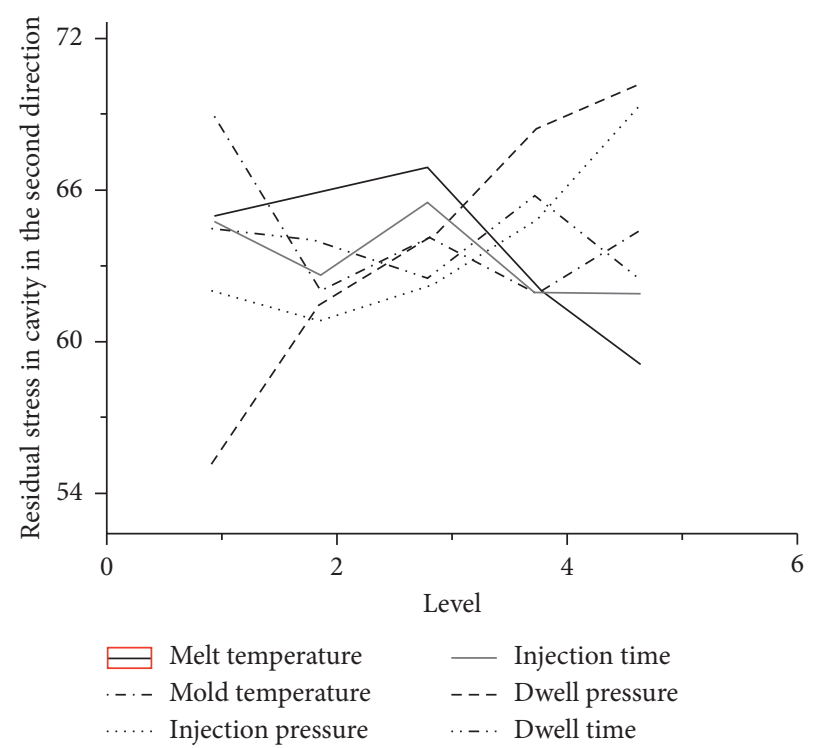

FIGURE 11: The influence of various factors on the residual stress in cavity in the second direction of infusion bottle embryo parts by the orthogonal test.

in cavity in the second direction as evaluation index were selected, which is a single-objective function of parameter optimization. The index of each parameter was evaluated $M_{j}=(0.4,0.4,0.1,0.1)[20]$.

4.2. Comprehensive Objective Function. A comprehensive weighted objective function was established as follows:

$$
Y_{i}^{*}=\sum_{i=1}^{25}\left[Y(i, j) \times M_{j}\right],
$$

where $Y(i, j)$ is the evaluation index score value, $Y_{i}^{*}$ is the comprehensive weighted score values, and $M_{j}$ is the experimental evaluation index weight.

From the results of the comprehensive weighted score as shown in Table 2, it was found that, in the trial, the fifth group of trials had the lowest overall score, and Group 21 had the highest score. It can be seen that, in the bottle orthogonal experiment, the best parameters' combination was when the melt temperature reached $200^{\circ} \mathrm{C}$, the mold temperature reached $80^{\circ} \mathrm{C}$, the injection pressure was $50 \mathrm{MPa}$, the injection time was $2.1 \mathrm{~S}$, the dwell pressure was $44 \mathrm{MPa}$, and the dwell time was $40 \mathrm{~S}$. 
TABLE 7: The analysis table of comprehensive weighted score by orthogonal test.

\begin{tabular}{lcccccc}
\hline & $A$ & $B$ & $C$ & $D$ & $E$ & $F$ \\
\hline$K_{2}=K_{2} / 5$ & 76.794 & 81.74 & 79.164 & 81.006 & 78.036 & 77.336 \\
$K_{3}=K_{3} / 5$ & 79.34 & 79.814 & 75.452 & 81.702 & 80.412 & 81.572 \\
$K_{4}=K_{4} / 5$ & 80.312 & 77.66 & 77.85 & 81.284 & 75.518 & 75.93 \\
$K_{5}=K_{5} / 5$ & 89.076 & 71.21 & 76.626 & 68.946 & 75.804 & 74.006 \\
$R$ & 26.092 & 10.53 & 3.962 & 12.756 & 4.894 & 7,566 \\
Order & 1 & 3 & 6 & 2 & 5 & 4 \\
\hline
\end{tabular}

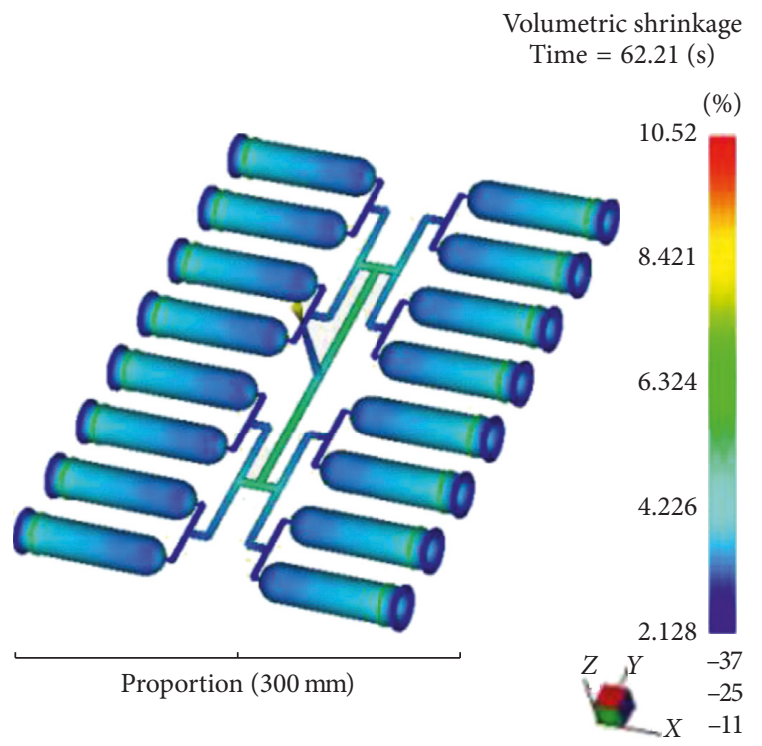

FIGURE 12: Volume shrinkage after optimization by weighted scoring.

4.3. Analysis of the Range of Comprehensive Weighted Grading Method for Infusion Bottle Injection Molding. The comprehensive weighted score values for each group by orthogonal experiments were calculated as shown in Table 2, and thus, it could be obtained that Group 5 had the best combination property. As this was the only best combination of these 25 trials without taking into account these 25 groups outside the case, the range analysis of comprehensive weighted score of each level would be necessary, so as to obtain various levels of factors contributing to the overall performance. Table 7 shows the influence degree of each factor towards injection molding combination property.

According to the results of the above analysis, the influence level order of each process parameter on shrinkage index was follows as follows: melt temperature $A>$ injection time $D>$ mold temperature $B>$ dwell time $F>$ dwell pressure $E>$ injection pressure $C$. From the analysis of range in Table 7, the optimum combination of process parameters for injection molding of infusion bottle is when the melt temperature reached $200^{\circ} \mathrm{C}$, the mold temperature reached $80^{\circ} \mathrm{C}$, the injection pressure was $40 \mathrm{MPa}$, the inject time was $2.1 \mathrm{~S}$, the dwell pressure was $40 \mathrm{MPa}$, and the dwell time was $40 \mathrm{~S}$.

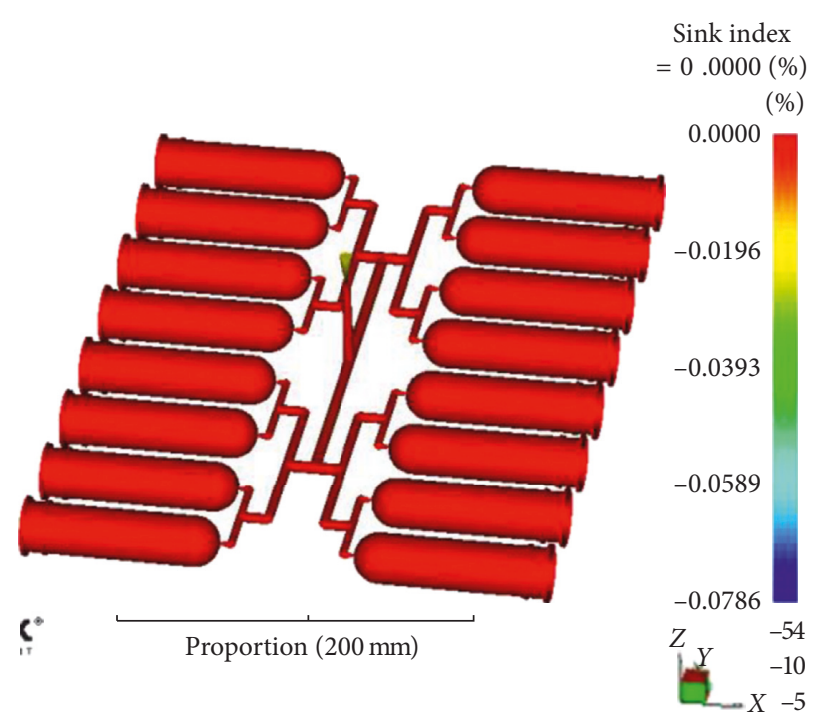

Figure 13: Sink index after optimization by weighted scoring.

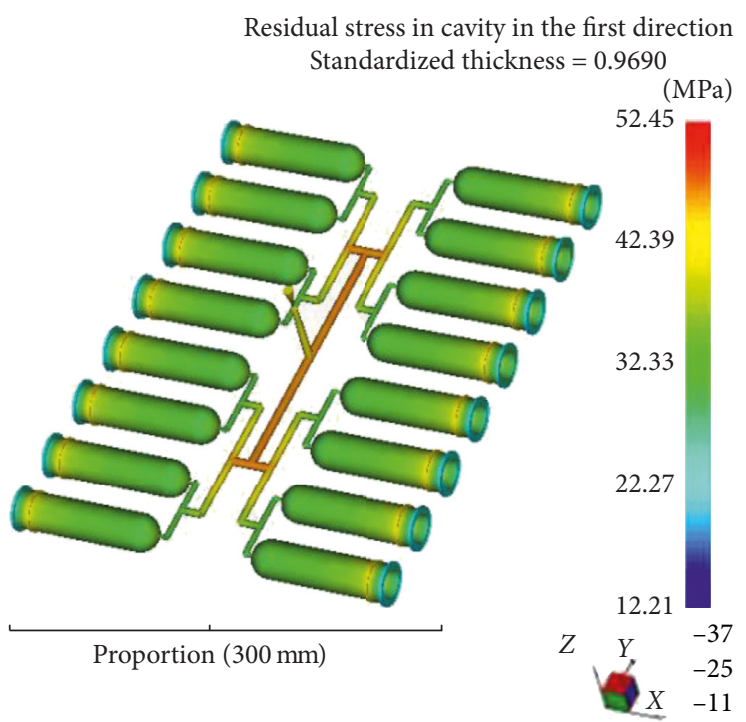

FIGURE 14: Residual stress in first cavity in the first direction after optimization by weighted scoring.

\section{Simulation Verification}

Setting the relevant process parameters of infusion bottle injection molding in Moldflow, the results of the injection molding simulation test can be obtained as the sink index was $0 \%$, the volumetric shrinkage was $10.52 \%$, the residual stress in cavity in the first direction was $52.45 \mathrm{MPa}$, and the residual stress in cavity in the second direction was $73.25 \mathrm{MPa}$, at which point the comprehensive performance is the best, as shown in Figures 12-15.

\section{Conclusions}

From this study, the following conclusions can be drawn:

(1) According to the structure of infusion bottle embryo and process requirements, an infusion bottle 


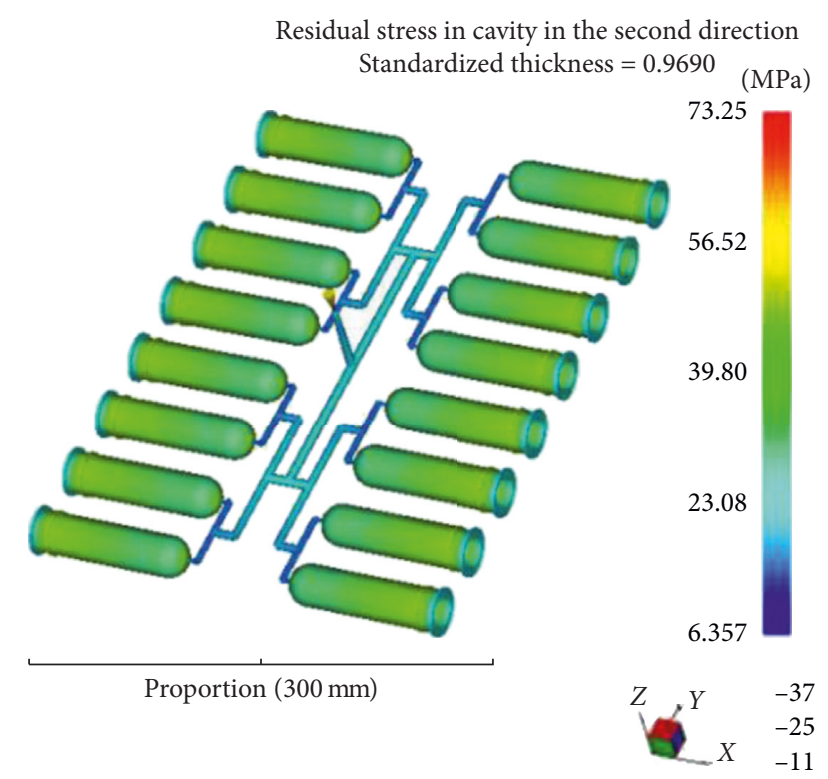

FIGURE 15: Residual stress in first cavity in the second direction after optimization by weighted scoring.

preform mold was designed, the plastic parts were distributed by two rows and eight columns, and the hydraulics-assisted method was used to process the side core-pulling.

(2) The orthogonal experiment table of L25 (5 6) was designed, and the sink index, the volumetric shrinkage, the residual stress in cavity in the first direction, and the residual stress in cavity in the second direction as its performance evaluation index were selected. The influence level order of each process parameter on volume shrinkage was obtained as follows: melt temperature $>$ injection time $>$ dwell time $>$ injection pressure $>$ dwell pressure $>$ mold temperature.

(3) The final optimal process parameters were obtained by the comprehensive weighted method: melt temperature $200^{\circ} \mathrm{C}$, injection time $2.1 \mathrm{~S}$, dwell time $40 \mathrm{~S}$, injection pressure $40 \mathrm{MPa}$, dwell pressure $40 \mathrm{MPa}$, and mold temperature $80^{\circ} \mathrm{C}$.

\section{Data Availability}

The data used to support the findings of this study are available from the corresponding author upon request.

\section{Conflicts of Interest}

The authors declare that they have no conflicts of interest.

\section{Acknowledgments}

This article belongs to the major projects of the "Natural Science Foundation of Anhui Province Education Department (KJ2016SD05 and KJ2017ZD12)." This article belongs to the project of the "Wuhu Scientific Research Project (2016cxy01).”

\section{References}

[1] C. Jiang-dong and L. Li-xin, "Optimum design of injection mold for hair dryer shell based on moldflow," Plastic, vol. 39, pp. 122-125, 2010.

[2] S. Ke, H. Qing-chun, and J. Xiao-ping, "Optimization design of injection mold cooling channels arrangement," Plastics Industry, vol. 40, pp. 25-26, 2014.

[3] W. Zili, Z. Shuyou, and Q. Lemiao, "Optimization method for process parameters coupling design oriented to green injection molding," Computer Integrated Computing System, vol. 12, pp. 48-50, 2015.

[4] C. Wei-qing, W. Sheng-kai, and R. Wei, "Optimized design of printer on the cover of injection mold based on moldflow," Plastic, vol. 16, pp. 101-102, 2012.

[5] C. Jin, T. Jianrong, and Y. Jiahong, "Multi-objective robust optimization of injection molding process parameters based on TOPSIS," Journal of Mechanical Engineering, vol. 27, pp. 39-40, 2011.

[6] W. Bo, S. Wenxue, L. Qingtao, and D. Haiping, "Optimization of injection process parameters for thin walled plastic parts of battery cover based on orthogonal experiment," Light Industry Machinery, vol. 4, pp. 50-51, 2014.

[7] H. Fengli, L. Ianping, Z. Meipeng, and X. Jinhong, MultiObjective Robust Design and Optimum Algorithm in Injection Molding Process, Journal of Tongji University, Shanghai, China, 2011.

[8] H. Zhang, "Structural design of mouse injection mold," Mechanical Research and Application, vol. 2, pp. 76-77, 2010.

[9] X. Zheng, B. Meng, and H. huang, "Design of injection mould for rear door handle based on CAE analysis," Die industry, vol. 10, pp. 43-46, 2010.

[10] L. Qiong, A Practical Guide to Plastic Injection Moldflow, Mechanical Industry Press, Beijing, China, 2008.

[11] H. Ming-Shyan and C. Chin-Feng, "Injection molding and injection compression molding of thin-walled light-guided plates with V-grooved microfeatures," Applied Polymer Science, vol. 12, pp. 1151-1159, 2011.

[12] Q. Huachang, Plastic Forming Process and Mold Design, Higher Education Press, Beijing, China, 2006.

[13] H. Jianming, "Improvement of air trap defects of power buttons based on flow simulation of moldflow," China Plastics, vol. 7, pp. 60-61, 2013.

[14] W. Guilong, Z. Guoqun, L. Huiping, G. Yanjin, and C. Liang, "Heat response simulation of variotherm injection molding and optimization of mold structure," Journal of Mechanical Engineering, vol. 2, pp. 18-20, 2009.

[15] C. Sheng-rong, X. Yong, Y. Guo-tai, and H. Cheng-hong, Research methods of parametric optimization for injection molding, China Plactics, vol. 4, 2003.

[16] F. Daver and B. Demirel, "A simulation study of the effect of preform cooling time in injection stretch blow molding," Journal of Materials Processing Technology, vol. 11, 2012.

[17] B. Demirel and F. Daver, "Experimental study of preform reheat temperature in two-stage injection stretch blow molding," Polymer Engineering \& Science, vol. 4, 2013.

[18] B. Demirel and F. Daver, "Effects of preform deformation behavior on the properties of the poly(ethylene terephthalate) bottles," Journal of Applied Polymer Science, vol. 4, 2012.

[19] R. A. Tatara, R. M. Sievers, and V. Hierzer, "Modeling the injection molding processing of a polypropylene closure 
having an integral hinge," Journal of Materials Processing Technology, vol. 1, 2006.

[20] L. Rongliang and H. Zehao, "Study on Multi-objective Optimization of Injection Parameters for Shell Product Based on CAE," Plastics Science and Technology, vol. 6, 2014. 


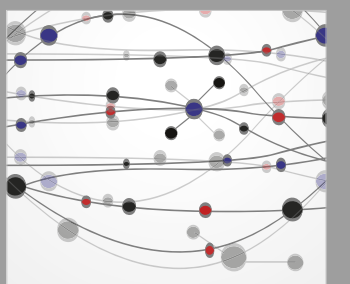

The Scientific World Journal
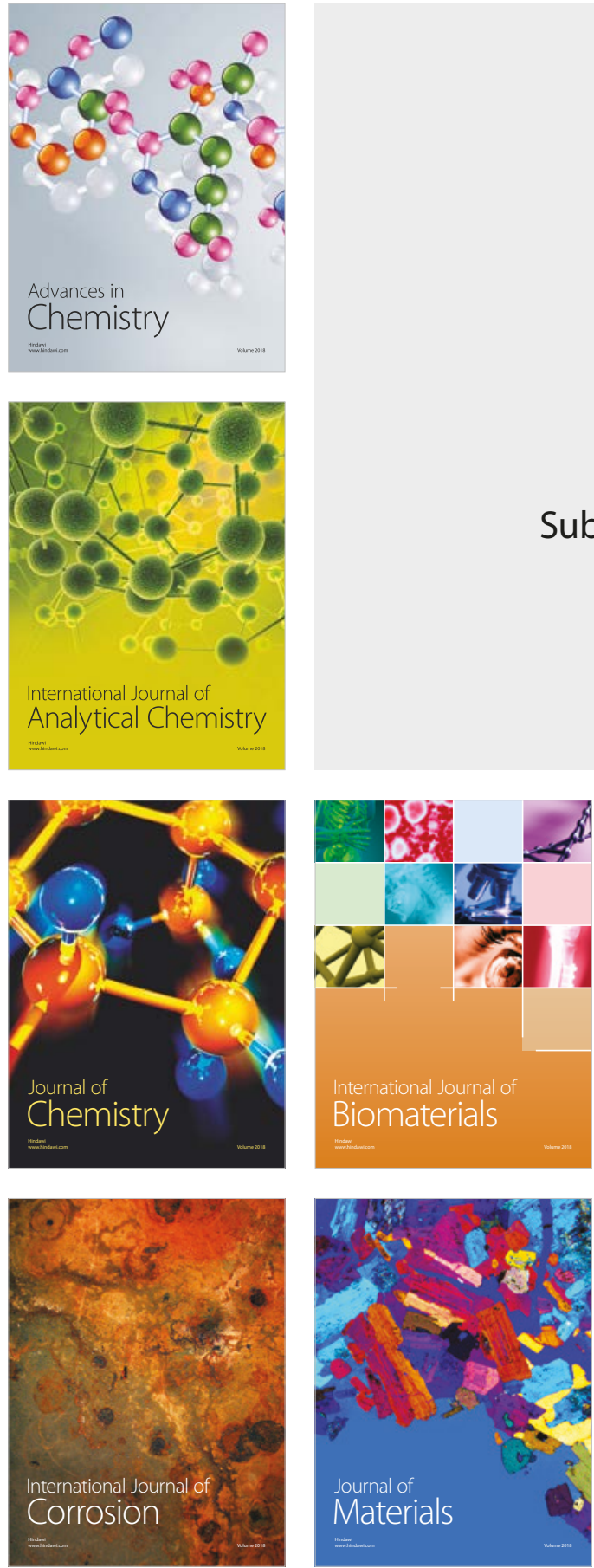

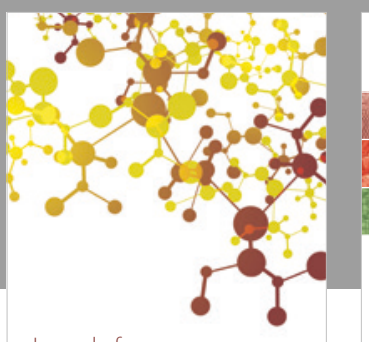

Journal of

Applied Chemistry
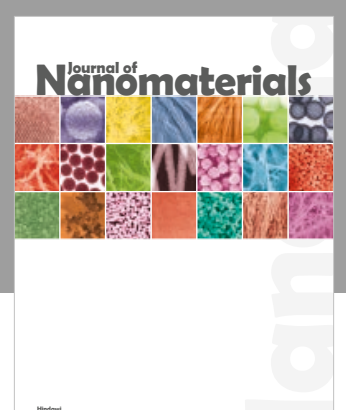

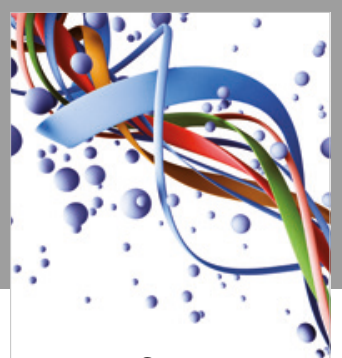

Scientifica

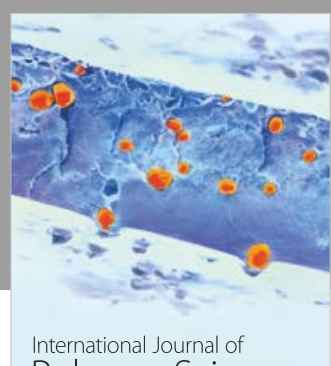

Polymer Science

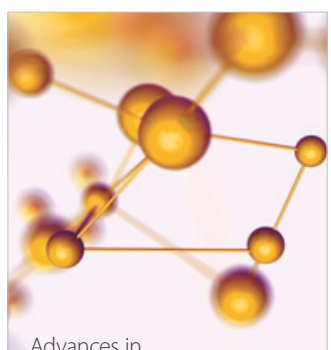

Physical Chemistry
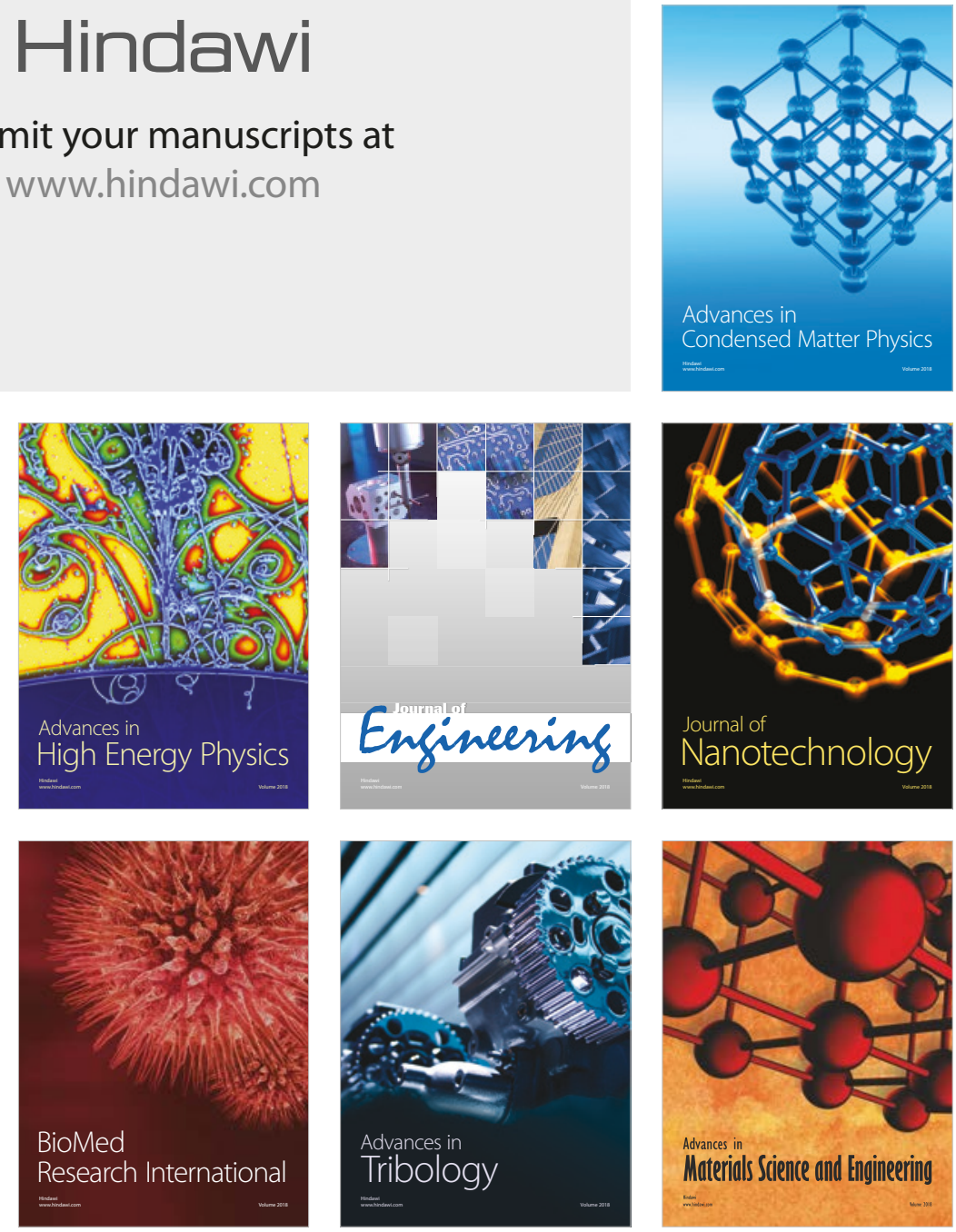